DOI 10.37882/2223-2982.2020.05.39

\title{
ЭЛЕКТРОННАЯ ПЛАТФОРМА LMS MOODLE КАК ОДНО ИЗ СРЕДСТВ ДИСТАНЦИОННОГО ИЗУЧЕНИЯ ЯЗЫКА ТЕКСТОВ ИГРОВЫХ ЧАТОВ
}

\section{ELECTRONIC PLATFORM LMS MOODLE AS ONE OF THE REMOTE MEANS OF LANGUAGE LEARNING IN THE TEXTS OF COMPUTER GAMES CHATS}

T. Yacovets

V. Zabirova

Summary: The present article is dedicated to the investigation of electronic platform LMS MOODLE as one of the remote e-learning means of English, the youth jargon in the texts of gaming chats through the electronic educational course. Course content is structured and the main analysis of the elements is done. The authors postulate features of electronic platform LMS MOODLE for advanced study of computer jargon and investigate its nature, specific features, structural and functional characteristics.

Keywords: electronic platform, e-learning, remote learning, electronic educational course, youth jargon.

\author{
Яковец Татьяна Яковлевна \\ к.n.н., дочент, Сургутский государственный университет \\ jatja57@mail.ru \\ Забирова Венера Хаджиахметовна \\ старший преподаватель, Сургутский государственный \\ университет \\ zabirovav@mail.ru
}

Аннотация: В статье проводится исследование электронной платформы LMS MOODLE как одного из средств дистанционного изучения английского языка, молодежного жаргона текстов игровых чатов посредством электронного образовательного курса. Структурировано содержание и проведен анализ основных элементов курса. Авторы определяют возможности электронной платформы LMS MOODLE для углубленного изучения компьютерного жаргона, как нового, быстроразвивающегося пласта лексики, исследования его природы, отличительных черт, структурных и функциональных характеристик.

Ключевые слова: электронная платформа, электронное обучение, дистанционное обучение, электронный образовательный курс, молодежный сленг.

глийского языка, но и молодежного жаргона текстов игровых чатов; целью исследования является разработка спецкурса по изучению молодежного сленга текстов игровых чатов.

Опираясь на существующие определения дистанционного обучения, можно утверждать, что дистанционное обучение - это такая форма учебного процесса, в которой используются традиционные и инновационные способы обучения, основывающаяся на принципе самостоятельного получения знаний, предполагающая в основном телекоммуникационный принцип доставки обучаемому базового учебного материала и интерактивное взаимодействие обучаемых и преподавателей как непосредственно в процессе обучения, так и при оценке полученных ими в процессе обучения знаний и навыков[8,2]. Главная составляющая дистанционного образования - дистанционное обучение, имеющее определенные средства приема и передачи данных, единых протоколов их взаимодействия, программное обеспечение, группу административного управления.

Дистанционное обучение основано на новых методах представления данных и учебных материалов в электронном виде и использовании Internet технологий 
для доставки электронных учебных материалов обучающимся. Благодаря развитию Интернета и современных методов общения и обмена данными становится возможным создавать и применять в обучении новые способы: электронные конспекты, энциклопедии, тесты, анкеты и т.д. Одним из вариантов использования таких методов и технологий является Learning Management System "Modular Object-Oriented Dynamic Learning Environment" (LMS MOODLE), что переводится с английского как: Система управления обучением “Модульная объектно-ориентированная динамическая учебная среда", представляющая собой систему управления содержимым сайта, специально разработанная для создания качественных online-курсов преподавателями.

Дистанционная платформа LMS MOODLE является одной из самых распространённых технологий, которая способствует оптимизации и интенсификации образовательного процесса в рамках самых разнообразных образовательных тенденций и программ, а именно, в процессе обучения английскому языку [10, с.70].

Рассмотрим ряд преимуществ платформы LMS MOODLE в изучении иностранного языка: возможность создания авторских курсов по иностранным языкам; наличие специальных систем регулирования контентом, которое позволяет как преподавателю, так и студенту постоянно следить за темпами и результатами прохождения курса; большая интерактивность и коммуникативная направленность, продвигающая процесс дистанционного обучения к взаимодействию преподавателя и студента в режиме реального времени; наличие широкого спектра мультимедийных возможностей (просмотр видеофрагментов, прослушивание аудиозаписей, флэш-игры, анимация и т.п.), являющихся эффективным средством повышения мотивации к изучению иностранного языка; возможность организовывать коммуникацию между преподавателем и студентами, а также между самими студентами, оперативно информировать участников курса о текущих или предстоящих событиях, активно взаимодействовать в режиме реального времени, проверять выполненные задания друг у друга, обмениваться файлами любых форматов, оценивать результаты обучения, в том числе в автоматическом режиме, контролировать посещаемость, активность студентов, время их учебной работы в сети, создавать электронный журнал для самоконтроля результатов [1, с.53].

Электронную платформу LMS MOODLE необходимо рассматривать также как специально организованную учебную деятельность, способствующую развитию компетенций обучающихся в целом и развитие коммуникативных компетенций в частности, формированию аналитических, проектировочных, коммуникативных способностей (готовность к самостоятельной, самообразовательной деятельности, к поиску, созданию и приме- нению новшеств в образовательном процессе, способность осуществлять взаимодействие в интерактивном режиме, применять индивидуализированные, деятельностно- и личностно-ориентированные технологии и методики обучения и т.д.).

Использование информационных платформ в образовательном и самообразовательном процессах обеспечивает контроль над всем учебным процессом, что является незаменимой частью всего образовательного процесса, выполняющей обратную связь между обучающимся и преподавателем. Объективность результата достигается, применяя информационные технологии для проверки знаний обучающихся. Данный контроль экономит время занятий из-за одновременной проверки знаний всех обучающихся, давая преподавателю возможность уделить время для индивидуальных и творческих заданий.

Структура LMS MOODLE и заложенные в эту платформу принципы оказались высоко эффективными и система LMS MOODLE завоевала признание мирового сообщества в качестве аналога известных коммерческих систем поддержки обучения, с которыми она успешно конкурирует, являясь бесплатно распространяемым программным комплексом [5, с.17]. Обучающая среда Moodle является на сегодняшний день одной из наиболее популярных систем поддержки учебного процесса дистанционного образования. Система Moodle была ориентирована изначально на университетское образование, впоследствии она активно использовалась для организации как довузовского, так и послевузовского обучения. На данный момент Moodle используют не только в университетах, но и в колледжах, училищах, школах, некоммерческих организациях и различных фирмах.

Важными преимуществами среды дистанционного обучения Moodle, обеспечивающими её широкую востребованность, являются мобильность, открытость, расширяемость, переносимость, широкая распространенность, бесплатность и т.д.

Особенно привлекательна эта среда для динамичных, быстро развивающихся дисциплин, когда важно дать студентам не только традиционную классификацию объекта изучения, но и познакомить их с последними открытиями и публикациями ученых по изучаемому предмету. Использование Moodle позволяет активно применять тренировочное и контрольное тестирование, осуществлять сдачу контрольных и лабораторных работ. Посредством форумов или личных сообщений студенты могут получить консультацию преподавателя по интересующим их вопросам, что позволяет экономить время и силы, получать индивидуальный подход при обучении. Система дистанционного обучения «Moodle» содержит 
широкий выбор инструментов по созданию, сопровождению и улучшению курсов и их эффективности. В ней каждый преподаватель имеет возможность подобрать для своей дисциплины необходимые для него инструменты для организации образовательного и самообразовательного процесса.

В рамках данной платформы существует несколько подходов к применению обучения иностранному языку. В настоящее время большую популярность имеет концепция «blended learning» или «смешанного обучения». В данной платформе LMS MOODLE доминирует именно концепция «смешанного обучения», которая предполагает комплекс традиционных и дистанционных средств и способов обучения иностранному языку, дополняющих и обогащающих друг друга, позволяющих сделать процесс интерактивным. «Смешанное обучение» представляет собой комплекс сетевого, классического и дистанционного обучения. Описывая особенности данного типа обучения, необходимо отметить, что в области обучения иностранным языкам этот тип является одним из наиболее оптимальных и встречающихся в связи с разным сочетанием подходов. В университетах обучение иностранному языку ведется по всем специальностям и направлениям подготовки; для каждой из них на платформе могут быть размещены рабочие программы для очной и заочной форм обучения с указанием формируемых компетенций, которые включают в себя: календарные планы занятий, учебные материалы по модулям, систему тестов, образцы зачетных и экзаменационных билетов, глоссарий, темы проектных заданий, этапы выполнения проектных заданий, образцы оформления презентации, статистики, темы докладов, задания для самостоятельной работы студентов, методические указания выполнения самостоятельной работы студентов. Если рассматривать методические разработки кафедр университетов на базе электронной платформы LMS MOODLE, то можно отметить, что все они систематизированы по форме обучения следующим образом: бакалавриат/специалитет; магистратура; заочное отделение; дополнительное образование; авторские курсы по специальностям, направленные на усвоение самостоятельной работы студентов всех курсов и направлений и специальностей на формирование языковых и коммуникативных компетенций, необходимых для изучения иностранного языка в рамках специальности, на формирование и развитие у обучающихся навыков профессиональной коммуникации в рамках научных мероприятий $[9$, c.120].

Данные виды электронной платформы LMS MOODLE имеют в наличии определенные типы файлов, которые позволяют разнообразно представить учебный материал. Например, большая часть документов Word и Power Point сохраняется в RTF; HTM редактор позволяет создавать документы непосредственно в LMS MOODLE; боль- шая часть справочной литературы (грамматика, образцы выполнения проектных заданий, презентации, статистики, доклада) представлена в PDF формате; в ходе обучения иностранному языку активно применяются презентации в программе Power Point как в качестве учебного материала (например, лекции), так и в качестве заданий для самостоятельной работы студентов; графические материалы, технические рисунки загружены как РІСТ и JPEG формате; кроме того, инструменты MOODLE позволяют постоянно загружать и обновлять медиа-контент (WAV, MP3, RAM, MOV, WMV) курсов - в результате этого студенты имеют возможность повышать уровень своих навыков аудирования и познакомиться с особенными передовыми разработками в области современной науки (видеофайлы либо ссылки на них) [1, с.35-46].

Благодаря ресурсам LMS MOODLE происходит становление профессиональных компетенций во время обучения иностранному языку за счет размещения курсов, направленных на изучение языка специальности с последующим его использованием как средства профессиональной коммуникации, в то время, когда на изучение языка как средства межкультурного обмена отведено недостаточно времени и внимания.

На сегодняшний день в действительности каждое высшее учебное заведение имеет платформу для дистанционного обучения. Уровень употребления может заметно модифицироваться в соответствии от года обучения и направления подготовки, так как создание курсов внутри платформы контролируется профессорско-преподавательским составом учебного заведения [4].

В современной лингвистике в последнее время много исследователей уделяют больше внимания речевым структурам, используемым в интернет-чатах. С появлением интернета язык перетерпел большие изменения, которые нельзя определить однозначно. Появились компьютерные онлайн игры, сопровождаемые комментариями и беседами игроков, различные социальные приложения, где пользователи общаются друг с другом, используя особые языковые единицы. Коммуникация в текстах игровых чатов - это специальный язык, на котором общаются игроки и их основная цель - экономить время и пространство написания [11].

В современное время молодежный жаргон является неотъемлемой частью каждого языка, независимо от этнических, социальных, типологических или каких-либо иных характеристик, что отражает специфичность современной жизни, тесно связанной с технологическим прогрессом. Вербальные номинации реальных объектов формируются многочисленными способами: слова могут претерпевать упрощение (структуры и семантики), сокращаться, на основе связи денотата с внешним 
миром (функционирование, форма, сопряженные с ним явления), появляются новые номинации - более упрощённые для активного пользования названия. Именно поэтому жаргон и сленг в наше время подвергаются пристальному вниманию лингвистов и исследование их возникновения и развития дает большой практический лингвистический материал, способствующий в какой-то мере пониманию языковых процессов развития и взаимодействия [7].

Очень популярны сегодня у молодёжи всего мира компьютерные игры. Коммуникация в игровых чатах состоит в основном из сленга и игровых жаргонизмов, которые формируются и используются игроками разных языковых этносов. Сетевые игры не знают границ ни политических, ни возрастных, ни социальных. Создаются благоприятные условия для переноса привычной модели общения в чате на реальную коммуникацию в рамках общественной деятельности и жизненной ситуации.

В данной статье мы приводим краткое описание специального курса для студентов лингвистических специальностей, целью которого является научное изучение и обоснования путей и способов формирования и функционирования класса компьютерной, жаргонной лексики.

Создание спецкурса на электронной платформе Moodle будет способствовать более углубленному изучению и пониманию молодежного жаргона. В содержание спецкурса входят следующие теоретические вопросы: определение понятий «сленг», «жаргон», «молодежный жаргон», «тексты игровых чатов», классификация жаргонов, особенности молодежного жаргона, компьютерные игры как один из источников молодежного жаргона, компьютерный жаргон, своеобразие и функции молодежного жаргона в текстах игровых чатов, функции компьютерного жаргона, основные тематические группы компьютерных жаргонов; тематический словарь игровых жаргонизмов английского языка, функциональные характеристики тематических групп.

Электронный образовательный курс включает в себя следующие виды работ: чтение теоретического материала, представленного в виде файлов и презентаций; просмотр компьютерных видеоигр; прослушивание речи участников игр; анализ данного вида речи (способы образования компьютерного жаргона и его функционирование); исследование молодежного сленга в приложении "Discord", где все сообщения остаются в памяти программы, что значительно облегчает исследование игровых жаргонизмов и современный сленг молодых людей по всему миру; создание тематической классификации для жаргонизмов текстов игровых чатов, используя словарь игровых жаргонизмов английского языка, словарь игровых жаргонизмов русского языка и приложения для общения “Discord”; определение функциональных характеристик выделенных элементов каждой тематической группы и т.д.

Пройдя спецкурс по изучению молодежного жаргона текстов игровых чатов студенты могут сделать вывод, что: жаргонизмы текстов игровых чатов имеют черты как молодёжного, так и профессионального жаргонов; молодёжный сленг метафоричен, эмоционален, оценочен и выразителен; в настоящее время популярным средством коммуникации являются социальные сети и различные приложения для общения; лингвистическую ценность представляет собой изучение различных коммуникаций посредством приложений, которые появились недавно и позволяют извлекать из своих хранилищ переписок нужную информацию; особенностью компьютерного жаргона является то, что его письменная форма преобладает над устной, это позволяет нам сравнить его с литературным языком, основываясь на его большом количестве языковых функций[6].

Таким образом, мы видим, что в современной лингвистике и методике преподавания иностранных языков интернет коммуникация рассматривается как особая сфера коммуникации, в которой встречаются типичные особенности устной и письменной форм речи. Экономия и усилий со стороны отправителя обуславливает использование различных новых способов выражения для достижения большей эмоциональности неформального общения. Дальнейшее изучение этого быстро развивающегося и изменяющегося пласта лексических единиц может способствовать систематизации и развитию лингвистических взглядов на молодежный жаргон, а также иметь практическую значимость в обучении языкам.

Использование электронной среды обучения LMS MOODLE позволяет не только организовать процесс более глубокого изучения иностранного языка, но и эффективно управлять им, развивая как профессиональные и общекультурные компетенции, при этом достигается еще одна важная цель дистанционного обучения - формируются навыки самостоятельной работы студентов. Использование электронных средств позволяет отечественному образованию соответствовать современным мировым стандартам.

\section{ЛИТЕРАТУРА}

1. Белозубов Д.Г. Система дистанционного обучения Moodle. Изд-во ТТИ ЮФУ, 2008. - 146 с.

2. Бурдаев В.П., Бурдаева Л.В. Модуль преподавателя в современных информационных технологиях обучения // Искусственный интеллект 3’2004. - Клев, 2004. 
3. Гильмутдинов, А.Х. Электронное образование на платформе Moodle [Текст] / А.Х. Гильмутдинов, Р.А. Ибрагимов, И.В. Цивильский. - Казань, КГУ, 2008. - 17 с.

4. Интернет-ресурсы: Открытые технологии. Преимущества Moodle http://www.opentechnology.ru

5. арамышева Т.В. Изучение иностранных языков с помощью компьютера. В вопросах и ответах. СПб.: Союз,2001-83с.

6. Колесникова С.Ф., Король Е.В., Яковец Т.Я. Функционирование жаргонизмов в текстах игровых чатов: Актуальные проблемы научного знания. Новые технологии ТЭК-2018: материалы II Международной Научно-практической конференции / отв.редактор М.В.Баделина.- Тюмень:ТИУ, 2018.- С.290-293

7. Король Е.В., Яковец Т.Я. Способы формирования и заимствования жаргонизмов игровых чатов, проблемы их ассимиляции и перевода. Litera эл. журнал изд-во Notabene, от 10.2018 -Москва: «НБ-Медиа».- С.68-75

8. К Кравченя Э.М. Формирование информационной культуры у студентов педагогических вузов // Известия Международной академии высшей школы. Мн., 2003. 一 № 3 (25).

9. Мазур, 3.Ф. Использование информационных и коммуникационных технологий в инновационно-маркетинговой деятельности учителя-новатора. Барнаул: БГПУ, 2009. - 119-121с.

10. Официальный сайт системы управления курсами Moodle [Электронный ресурс]. - Режим доступа: http://http://moodle.org. - Загл. с экрана.

11. Яковец Т.Я., Король Е.В. Функционирование молодежного жаргона в текстах игровых чатов. // Современная наука: актуальные проблемы теории и практики. Серия «Гуманитарные науки», - 2018, -№10, -С. 182-187.

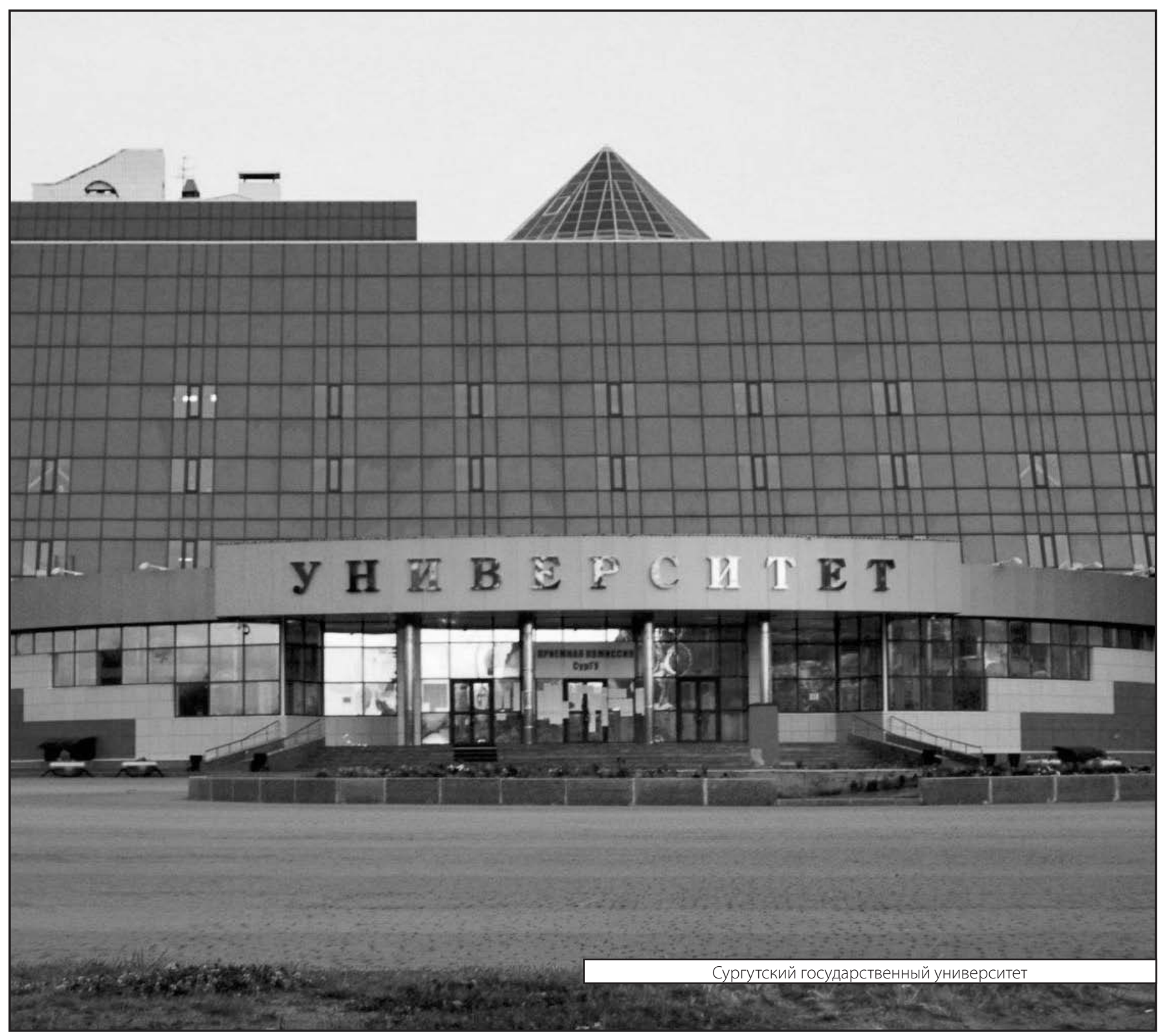

